\title{
New discoveries on the effects of desertification on the ground temperature of permafrost and its significance to the Qinghai-Tibet Plateau
}

\author{
XIE ShengBo $^{1}$, QU JianJun ${ }^{1,2,3^{*}}$, ZU RuiPing ${ }^{1}$, ZHANG KeCun $^{1}$ \& HAN QingJie ${ }^{1}$ \\ ${ }^{1}$ Key Laboratory of Desert and Desertification, Cold and Arid Regions Environmental and Engineering Research Institute, Chinese Academy of \\ Sciences, Lanzhou 730000, China; \\ ${ }^{2}$ Dunhuang Gobi and Desert Research Station, Cold and Arid Regions Environmental and Engineering Research Institute, Chinese Academy of \\ Sciences, Dunhuang 736200, China; \\ ${ }^{3}$ Gansu Center for Sand Hazard Reduction Engineering and Technology, Lanzhou 730000, China
}

Received September 22, 2011; accepted November 14, 2011; published online December 14, 2011

\begin{abstract}
The desert and permafrost conditions of the Qinghai-Tibet Plateau are unique. However, the effects of desertification on the ground temperature of permafrost are currently unclear. Recently, understanding this problem has become more urgent because of increasing desertification on the plateau. For this reason, an observational field experiment was undertaken by the authors at Honglianghe on the Qinghai-Tibet Plateau. Thermistor ground temperature probes were used, and synchronized contrasting observations were made in an open area. Observations of the ground temperature of permafrost below sand layers with a range of thicknesses were made from May 2010 to April 2011. The sand layers were found to play a key role in the protection of the underlying permafrost. The ground temperature below a permafrost table overlain by a thick sand layer was lower than that of the average annual temperature for the natural ground surface, and the temperature drop was roughly constant at $0.2^{\circ} \mathrm{C}$. During the warmer part of the year (May to September), the maximum temperature drops over the five months were 3.40, 3.72, 4.85, 3.16, and $1.88^{\circ} \mathrm{C}$, respectively. The ground temperature near a permafrost table overlain by a thin sand layer was also lower than that of the average annual temperature for the natural ground surface. However, in this case the average of the annual maximum temperature drop was significantly less, $0.71^{\circ} \mathrm{C}$. The scientific significance of our preliminary conclusions is not only to present an exploration of the interaction between desertification and permafrost, but also to provide new engineering ideas for protecting the permafrost in regions where construction is required on the Qinghai-Tibet Plateau.
\end{abstract}

desertification, Qinghai-Tibet Plateau, ground temperature of permafrost, new discoveries

Citation: Xie S B, Qu J J, Zu R P, et al. New discoveries on the effects of desertification on the ground temperature of permafrost and its significance to the Qinghai-Tibet Plateau. Chin Sci Bull, 2012, 57: 838-842, doi: 10.1007/s11434-011-4901-5

In addition to latitude and elevation [1], the ground temperature of permafrost on the Qinghai-Tibet Plateau is also affected by local factors such as geological structures, landforms, desertification, water content, lithology, vegetation, snow sediment, and water coverage [2-4]. The influence of these local factors can even surpasses the regional climatic background under specific conditions $[5,6]$. These local factors often affect engineering decisions that enable

*Corresponding author (email: qujianj@1zb.ac.cn) the protection and stabilization of permafrost during construction projects in regions of the Qinghai-Tibet Plateau [7]. Desertification, an important local factor that affects the ground temperature of permafrost, is widespread in the permafrost regions covering $1.49 \times 10^{6} \mathrm{~km}^{2}$ of the Qinghai-Tibet Plateau. However, the effect of desertification on the ground temperature of permafrost is rarely investigated, and no significant conclusions have been drawn.

Previous studies [8-10] have shown that ground temperature in regions of windblown sand within the permafrost 
zone of the Qinghai-Tibet Plateau are higher than in regions not affected by sand, which may accelerate the degradation of permafrost. Recent studies [11-13] have shown the dual nature of the sand layer on the ground temperature: the ground temperature in a zone of thick sand coverage is higher than that in a non-sandy zone, thereby accelerating the thawing of permafrost, whereas the ground temperature in a zone of thin sand layer coverage is lower than that in a non-sandy zone, thereby protecting the permafrost. Because of the conditions and technical limitations of data collection for this work, the above conclusions comprise only sporadic observations and simple reasoning. Moreover, the conclusions lack long-term observations and systematic research; therefore, they vary, and sometimes even contradict one another.

Recent desertification has developed [9] as the climate has changed on the Qinghai-Tibet Plateau [14-16], and the desertified land area has now covers $3.303 \times 10^{5} \mathrm{~km}^{2}[17,18]$. Thus, research on the impacts of desertification on the permafrost environment is urgent. In 2010, an observational field experiment examining windblown sand, the ground temperature of permafrost, and meteorological conditions was set up by the authors at Honglianghe on the Qinghai-Tibet Plateau to reveal the effects of desertification on the ground temperature of permafrost.

Honglianghe, located at $35^{\circ} 03^{\prime} 13^{\prime \prime} \mathrm{N}, 93^{\circ} 01^{\prime} 07^{\prime \prime} \mathrm{E}$ and an elevation of $4658 \mathrm{~m}$, was chosen as the experimental site for this work. This region of relatively flat terrain in the hinterland of the Qinghai-Tibet Plateau has sparse vegetation, strong aeolian sand activity, surfaces covered by sand layers of different thicknesses, and large areas of continuous underground permafrost. Thus, it is an ideal place to study the relationship between desertification and permafrost. Three temperature observation holes, located in a thick sand layer, a thin sand layer, and a natural (unsedimented) ground surface were established in the field. The sand layers formed naturally from 2001 to 2006, and had thicknesses of approximately $1.20,0.10$, and $0 \mathrm{~m}$ and areas of $20 \mathrm{~m} \times 15 \mathrm{~m}$, $500 \mathrm{~m} \times 50 \mathrm{~m}$, and $0 \mathrm{~m}^{2}$, respectively. The depth and diameters of the temperature observation holes were all set to 20 $\mathrm{m}$ and $0.12 \mathrm{~m}$, respectively. The distance of the temperature observation holes from each another was set at $50 \mathrm{~m}$ to ensure the maximum similarity of local background factors, such as strata, water content, and permafrost development conditions. Moreover, to prevent the sand layers from deflating, some sand-blocking and sand-fixing measures were adopted to maintain a stable sand layer thickness. The ground temperature observation began at the bottom of the sand layers; thus, the depth of observation does not include the thickness of the corresponding sand layer. Considering that the boreholes themselves disrupt the heat balance of the permafrost, the ground temperature observations were delayed for 60 days after drilling so that the heat balance of the temperature observation holes and the surrounding permafrost could recover and maintain a stable state.
Ground temperature was measured using a platinum thermistor probe (with an accuracy of $0.01^{\circ} \mathrm{C}$ ). The temperature-measuring holes were $<10 \mathrm{~m}$ deep and $0.5 \mathrm{~m}$ apart. The interval at a depth of 10 to $20 \mathrm{~m}$ was $1 \mathrm{~m}$, and the probe was bound to the cable, which is a PVC hose-sealed cable placed in a $32 \mathrm{~mm}$ aluminum-plastic pipe to prevent water infiltration. The aluminum-plastic pipe was then vertically placed in the borehole, and the circular connector between the outer wall of the aluminum-plastic pipe and the wall of the hole was filled with dry fine sand. The cable was connected to the data logger, and the data measured by the thermistor were recorded every hour from May 2010 to April 2011.

During the year-long continuous observation, the ground temperature of the underlying permafrost below sandy sediment of different thicknesses was shown to exhibit a marked difference compared with that of the natural ground surface without sandy sediment (Figure 1). The differences were manifested in a range of aspects that are described below.

The ground temperature below the thick sand layer was bounded near the permafrost table. The ground temperature of the permafrost below this depth was below that of the natural ground surface all year, regardless of the season. Moreover, the scale of the temperature drop was roughly constant at $0.2^{\circ} \mathrm{C}$, whereas the ground temperature in the active layer above the depth varied depending on the season. During the warmer months of May to September, the surface temperature was positive in value and higher than the ground temperature. At the same time, ground temperature below the thick sand layer was significantly lower than that of the corresponding natural ground surface. Furthermore, the temperature measured nearer to the surface had greater differences. The maximum value occurred near the surface, and the amplitudes of the temperature drop during the five months were $3.40,3.72,4.85,3.16$, and $1.88^{\circ} \mathrm{C}$, respectively. Moreover, the amplitude of the temperature drops decreased with increasing depth. During the colder months of November to March, the surface temperature was negative in value and far lower than the ground temperature, whereas the ground temperature in the active layer below the thick sand layer was higher than that of the natural surface in the negative value. However, the whole permafrost layer below the surface remained in a frozen state. During the months of April and October, frequent positive and negative variations in the daily surface temperature occurred [19]. This coincides with the transition stages for the freeze-thaw transformation of the active permafrost layer. During the month of April, the soil thaws, and the ground temperature of the active layer below the thick sand layer was lower than the temperature of the natural surface. During the month of October, the soil froze, and the ground temperature of the active layer below the thick sand layer was higher than the temperature of the natural surface.

The ground temperature near the permafrost table below the thin sand layer was significantly lower than the temperature 

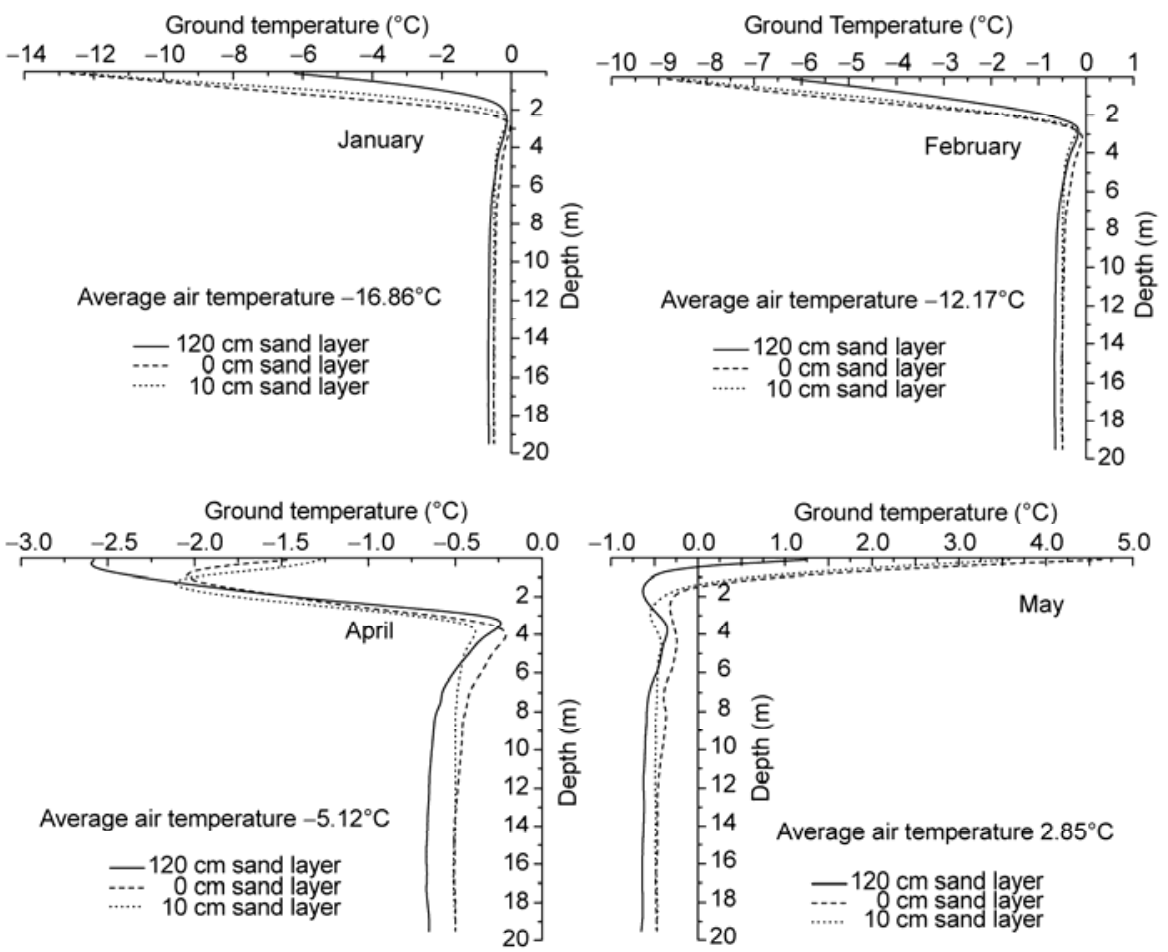

Ground temperature $\left({ }^{\circ} \mathrm{C}\right)$

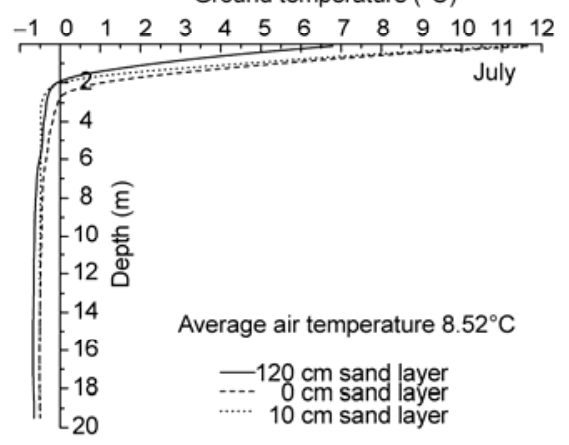

Ground temperature $\left({ }^{\circ} \mathrm{C}\right)$
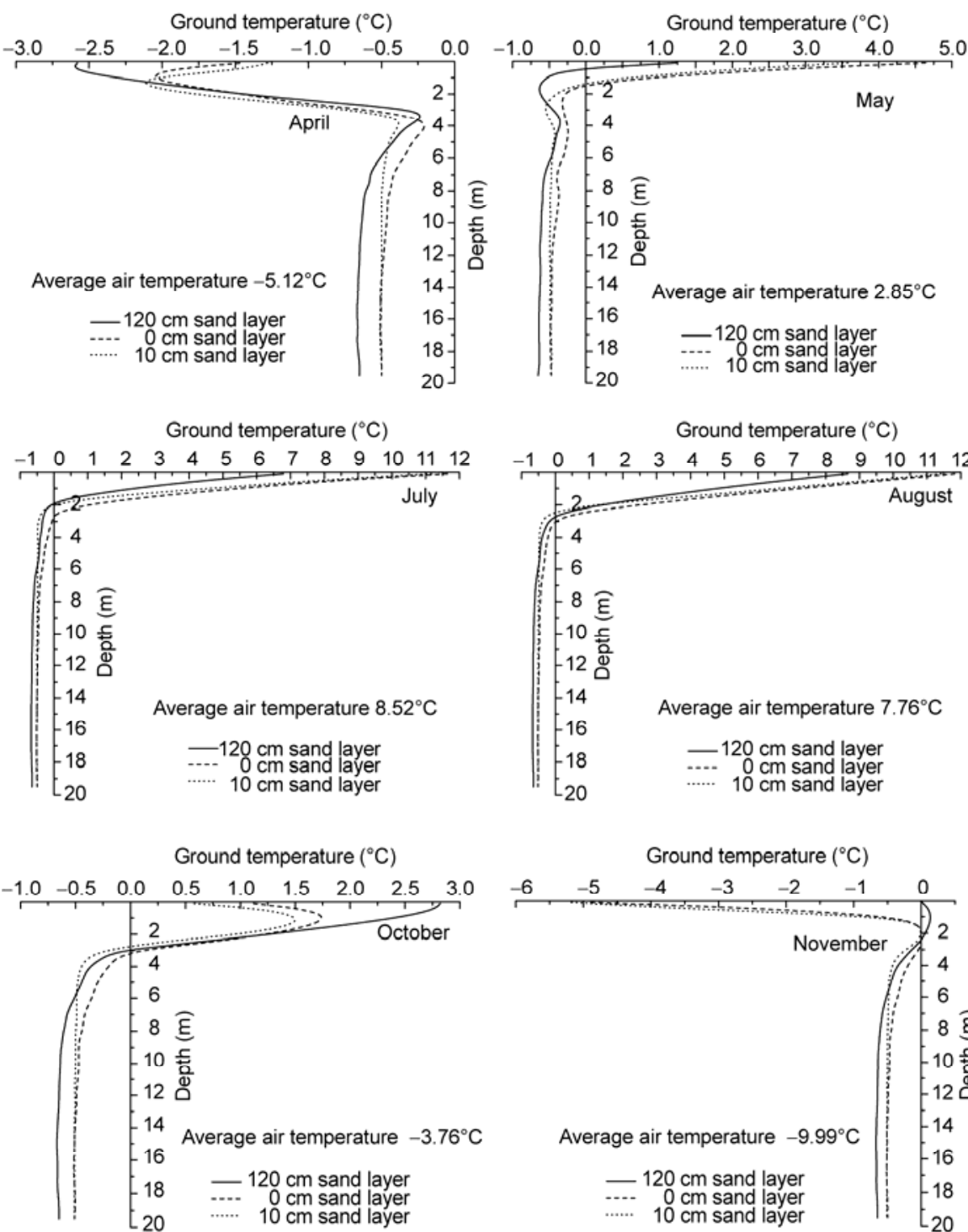

Ground temperature $\left({ }^{\circ} \mathrm{C}\right)$
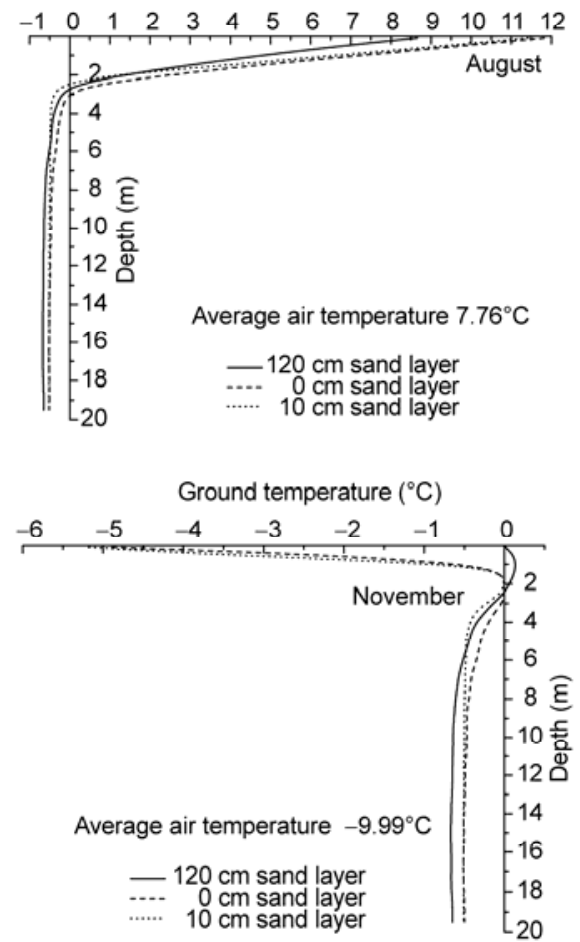
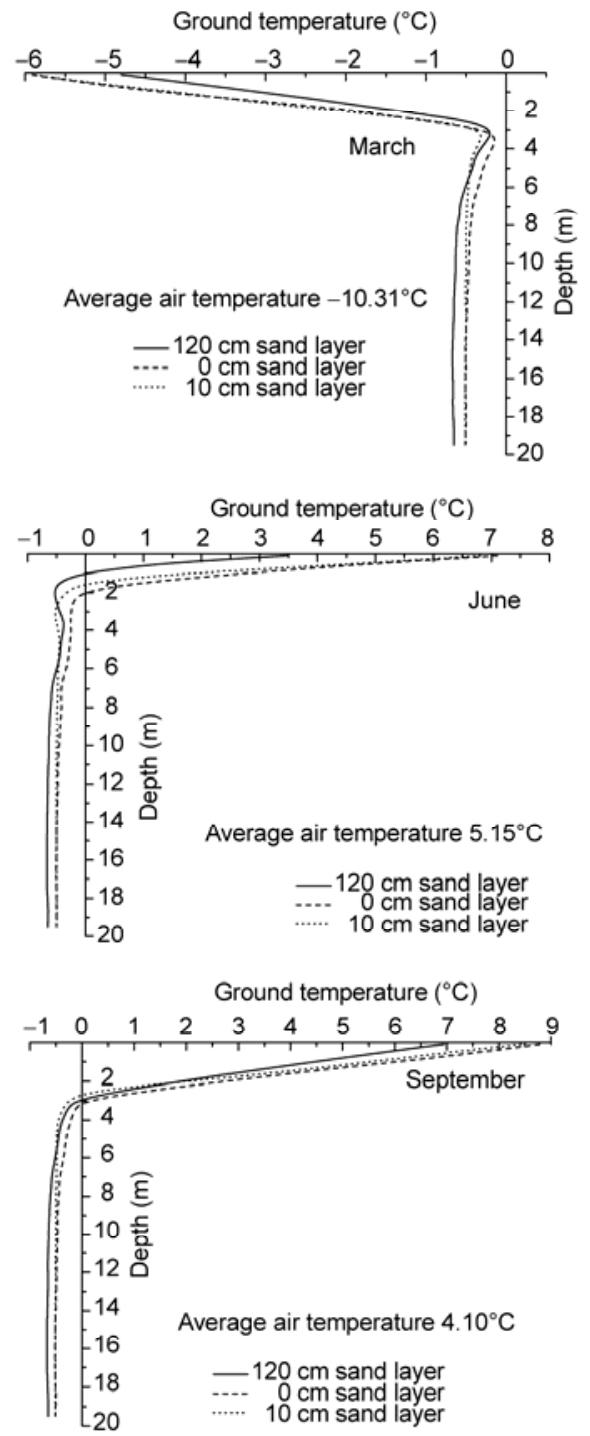

Ground temperature $\left({ }^{\circ} \mathrm{C}\right)$

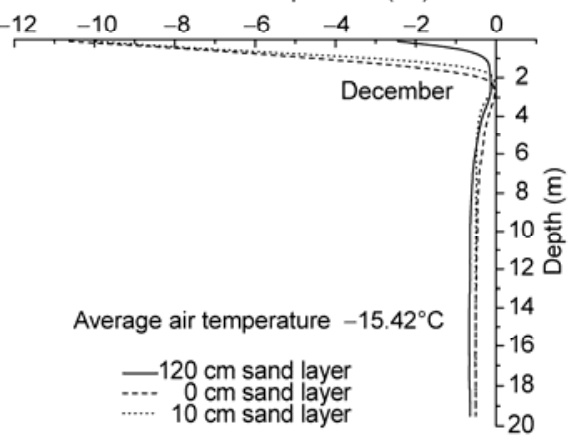

Figure 1 Monthly average ground temperature curve and air temperature at Honglianghe on the Qinghai-Tibet Plateau (May 2010 to April 2011).

of the corresponding natural surface throughout the year, and the average annual maximum temperature drop was $0.71^{\circ} \mathrm{C}$. However, the ground temperature near the surface and in the underlying permafrost layer did not differ significantly. The temperature drop was most evident near the permafrost table, while the temperature drop above and be- low the permafrost table gradually decreased.

The amplitude of the ground temperature drop near the permafrost table below the thin sand layer was even larger than that of the corresponding thick sand layer. In contrast, the amplitude of the temperature drop below the permafrost table under the thick sand layer was larger than that of the 
thin sand layer. The annual ground temperature range in the active layer below the thick sand layer was lower than that of the corresponding thin sand layer and natural ground surface. Also, variations in the ground temperature depended on the different seasons.

In addition, the permafrost table below the sand layer rose during the observation period. The permafrost table in the temperature observation hole of the natural ground surface was $3.2 \mathrm{~m}$, whereas that of the thick and thin layers were 2.9 $\mathrm{m}$ and $2.8 \mathrm{~m}$, respectively, which ascended by $0.3 \mathrm{~m}$ and 0.4 $\mathrm{m}$, respectively, as compared with the natural ground surface.

When desertification occurs on the Qinghai-Tibet Plateau, sand covers the ground surface, where the reflectivity of the sand surface can reach 0.25 to 0.4 . Compare this to the reflectivity of a bare surface, which is only 0.1 to 0.25 . The reflectivity of the sand-covered surface increases and the net radiation of the surface decreases because of the much higher reflectivity of sand than of a bare surface. A large portion of heat is emitted to the atmosphere through longwave surface radiation and the turbulent exchange of the land-atmosphere system. Therefore, the heat transferred by soil heat flux to the permafrost below the sand layer decreases, resulting in the lower ground temperature of the soil covered by the sand layer than the temperature of the natural surface during the ascension of the permafrost table, as proven by the surface heat balance for the Qinghai-Tibet Plateau [20]. For example, in the permafrost regions of the Qinghai-Tibet Plateau, the altitude is high, land cover belongs to the alpine frost desert steppe, vegetation is sparse, precipitation is low, evaporation is weak, the heat transferred by latent heat in water is small, and the heat exchange of the land-atmosphere system is dominated by the sensible heat transmission [21]. In other words, water plays no role in the land surface-atmosphere heat exchange in the permafrost regions of the Qinghai-Tibet Plateau. Under certain atmospheric driving conditions, the heat flux of soil is influenced by a number of factors, such as the thermal inertia, the thermal diffusion coefficient, and water content [22,23]. The sand layer has a lower water content, less thermal inertia, smaller soil heat flux, and smaller ground temperature amplitude [24] as compared with a natural soil layer. Moreover, the sand layer is a weak pervious conductor with poor heat conductivity [25]. During the warmer months of the year, the surface air temperature measured in the temperature observation holes positioned as above, and the sand layer blocked the downward transfer of surface heat. Therefore, the ground temperature in the thick sand temperature observation hole was significantly lower than that measured in the natural surface temperature observation hole. The temperature drop was most evident in the active layer. However, the temperature drop amplitude decreased with increasing depth because of the heat transfer from under the ground. During the colder months of the year, the surface air temperature was negative in value, and far lower than the ground temperature. Similarly, the sand layer prevented the downward transfer of the surface cold source. Thus, the ground temperature of the active layer was higher than the temperature of the natural surface in the negative value and the annual range decreased.

These results are similar to those of Wang et al. for the Qumar River on the Qinghai-Tibet Plateau [26]. For the surface of the thin sand temperature observation hole, the heat-blocking effect during summer was small because it only involved a $0.1 \mathrm{~m}$ thick sand layer, and the winter cold-blocking effect was minimal. The transfers of summer heat and winter cold to the active layer were relatively easier for the case of the thin rather than thick sand layer. Thus, ground temperature differences in the active layer, thin sand temperature observation holes, and natural surface were less evident. Moreover, nearly no difference existed between the ground temperature and the temperature of the natural surface temperature observation hole because of the heat transfer from the interior of the earth coupled with the limited effect of the thin sand layer. The ground temperature drop near the permafrost table in the thin sand temperature observation hole was evident throughout the year because of the small heat effect from both the surface and the underground boundary layer; however, the ground temperature difference between the above active layer and underlying permafrost layer gradually decreased.

In the desert permafrost regions of the Qinghai-Tibet Plateau, the ground temperature below thick sand layer are bounded near the permafrost table, in contrast with the situation at a natural ground surface. The ground temperature of the permafrost below this table depth decreased during the observation period, with a temperature drop of roughly $0.2^{\circ} \mathrm{C}$. Moreover, the ground temperature in the active layer above varied seasonally (i.e. the ground temperature decreased during the warmer half of the year and increased during the colder half of the year). The annual range decreased, with April and October being transitional stages. The ground temperature near the permafrost table below the thin sand layer was decreased throughout the year, whereas the ground temperature difference in the upper active layer and underlying permafrost layer only gradually decreased. Overall, desertification plays a key role in protecting the underlying permafrost on the Qinghai-Tibet Plateau.

Changes in the ground temperature of the permafrost below a sand layer can be attributed to differences in reflectivity and heat conductivity between the sand layer and natural ground surface of the Qinghai-Tibet Plateau. A thicker sand layer causes a stronger heat-blocking effect because of its high reflectivity and poor heat conductivity.

In summary, the continuous year of observations during 2010 and 2011 preliminarily showed that sand layers play a key role in protecting underlying permafrost in the desert permafrost regions of the Qinghai-Tibet Plateau. Although the ground temperature of the active layer in the temperature observation hole below the thick sand layer was higher than the temperature of the corresponding natural ground 
surface during the colder half of the year, the whole permafrost layer below the ground surface was in a frozen state, and there was no problem with thawing. Thus, the actual protection effect of the sand was not required. The development of seasonal thawing onsets rapidly in early June and continues through to early September (i.e. the warmer half of the year) on the Qinghai-Tibet Plateau [27]. This is the period when a thick sand layer can best protect the underlying permafrost. Therefore, the protective effect of the thick sand layer on the permafrost is slightly better than that of a thin sand layer. Surface building foundations or other structures will not deform under the condition of small dynamic or static pressures. The preferred method of sand coverage should be considered in future investigations of permafrost protection under the former dynamic and static pressure conditions. This work should provide new ideas and engineering constraints to assist in developing protective infrastructure in permafrost environments on the Qinghai-Tibet Plateau.

This work was supported by the National Natural Science Foundation of China (40930741 and 41071009) and the Knowledge Innovation Program of Chinese Academy of Sciences (KZCX2-YW-329). The authors would like to thank Profs. Liu Yongzhi and Dong Guangrong from the Cold and Arid Regions Environmental and Engineering Research Institute of the Chinese Academy of Sciences for their assistance in the experiment and paper writing. We also thank the three anonymous reviewers' useful comments and the editor's valuable suggestions for improving this manuscript.

1 Li S X, Wu T H. J Glaciol Geocryol, 2005, 27: 627-632

2 Wang S L, Ding Y J, Zhao L. Plateau Meteorol, 2002, 21: 85-89
3 Pang Q Q, Zhao L, Li S X. J Glaciol Geocryol, 2011, 33: 349-356

4 Cheng G D. J Glaciol Geocryol, 1979, 1: 39-43

5 Williams P J, Smith M W. The Frozen Earth-Fundamentals of Geocryology. Cambridge: Cambridge University Press, 1989. 59-82

6 Camill P, Clark G S. Am Nat, 1998, 151: 207-222

7 Cheng G D. Sci China Ser D-Earth Sci, 2004, 47: 704-709

8 Huang Y Z, Guo D X, Zhao X F. J Glaciol Geocryol, 1993, 15: 52-57

9 Qiu G Q. Proceedings of the Chinese Conference on Glaciology and Geocryology (Geocryology Volume). Beijing: Science Press, 1982. 19-26

10 Yang M X, Wang S L, Yao T D, et al. Cold Reg Sci Technol, 2004, 39: 47-53

11 Wang S L, Xie Y Q. J Desert Res, 1998, 18: 137-142

12 Wang S L, Zhao L, Li S X. J Desert Res, 2002, 22: 33-39

13 Lv L Z, Jin H J, Wang S L, et al. J Glaciol Geocryol, 2008, 30: 546-554

14 Yang B, Tang L Y, Li C H, et al. Chin Sci Bull, 2010, 55: 1169-1177

15 Kang S C, Zhang Y J, Qin D H, et al. Chin Sci Bull, 2007, 52: 825-831

16 Duan A M, Wu G X, Zhang Q, et al. Chin Sci Bull, 2006, 51: 1396-1400

17 Dong Y X. J Desert Res, 1999, 19: 251-255

18 Zhang D S, Gao S Y. J Desert Res, 2007, 27: 367-372

19 Yang M X, Yao T D, Gou X H, et al. Chin Sci Bull, 2007, 52: 136-139

20 Xie Y Q, Wang H M, Li G. Annual Report of the Comprehensive Observatory and Research Station on the Qinghai-Tibet Plateau, Chinese Academy of Sciences, Vol. 3. Lanzhou: Lanzhou University Press, 1995. 56-62

21 Ji J J, Huang M. Adv Earth Sci, 2006, 21: 1268-1272

22 Bhumralkar C M. J Appl Meteorol, 1975, 14: 1246-1258

23 Yang K, Koike T. J Appl Meteorol, 2005, 44: 546-550

24 Zhang Q, Huang R H. J Appl Meteorol, 2004, 43: 1917-1928

25 Oke T R. Boundary Layer Climates. New York: Wiley and Sons, 1978. 43-49

26 Wang S L, Zhao X M. J Glaciol Geocryol, 1999, 21: 351-356

27 Zhou Y W, Qiu G Q, Guo D X, et al. Geocryology in China (in Chinese). Beijing: Science Press, 2000. 65-73

Open Access This article is distributed under the terms of the Creative Commons Attribution License which permits any use, distribution, and reproduction in any medium, provided the original author(s) and source are credited. 